\title{
Lethal and resistant partners
}

DOI:

10.1038/nrc2183

URLs

NSCLC

http://www.cancer.gov/

cancertopics/types/lung

FGD4

http://www.ncbi.nlm.nih.gov/ sites/entrez?Db=gene\&Cmd= ShowDetailView\&TermToSearc $\mathrm{h}=121512$

\section{ACRBP}

http://www.ncbi.nlm.nih.gov/ sites/entrez?Db=gene\&Cmd= ShowDetailView\&TermToSearc $\mathrm{h}=84519$

\section{PSMA6}

http://www.ncbi.nlm.nih.gov/ sites/entrez? $\mathrm{Db}=$ gene\&Cmd= ShowDetailView\&TermToSearc $\mathrm{h}=5687$

HS6ST2

http://www.ncbi.nlm.nih.gov/ sites/entrez? Db=gene\&Cmd= ShowDetailView\&TermToSearc $\mathrm{h}=90161$

\section{ATP6V0D2}

http://www.ncbi.nlm.nih.gov/ sites/entrez?Db=gene\&Cmd= ShowDetailViewยTermToSearc $h=245972$

KRAS

http://www.ncbi.nlm.nih.gov/ sites/entrez?Db=gene\&Cmd= ShowDetailViewยTermToSearc $\mathrm{h}=3845$

\section{COL4A3BP}

http://www.ncbi.nlm.nih.gov/ sites/entrez? Db=gene\& $\mathrm{Cmd}=$ ShowDetailView\&TermToSearc $\mathrm{h}=10087$
Two recent publications in Nature and Cancer Cell have identified genes that can make cancer cells resistant or sensitive to paclitaxel.

Michael White and colleagues used a genome-wide small interfering RNA (siRNA) screen to identify genes that can sensitize non-small-cell lung cancer (NSCLC) cells to paclitaxel, a standard treatment for this type of tumour. The initial screen identified a core panel of 87 paclitaxel sensitizer loci. The authors picked six genes that were representative of the functional gene groups found in the screen, and showed that siRNA inhibition of each target sensitized cells to low levels of paclitaxel, but not other chemotherapeutic agents. So how do these genes act to sensitize cells to paclitaxel? Depletion of FGD4, an activator of the small GTPase CDC42 that is implicated in cell polarity and division, resulted in mitotic arrest, whereas depletion of the cancer/testes antigen ACRBP and the $\gamma$-tubulin ring component TUBGCP2 did not affect mitosis, but collaborated with paclitaxel to significantly increase multipolar spindle formation - a typical response in a cell that is sensitive to paclitaxel. Depletion of the proteasome subunit PSMA6, the heparin sulphate transferase HS6ST2 or a vacuolar ATPase subunit, ATP6V0D2, had no effect on mitotic spindle assembly, despite sensitizing cells to paclitaxel. These results indicate that proteins such as ACRBP might contribute to mitotic progression when overexpressed in situations where the mitotic spindle checkpoint is not robust, thus allowing cells to evade paclitaxel-mediated mitotic arrest.

Julian Downward and colleagues also used an siRNA library to look for genes that determine sensitivity to paclitaxel and other chemotherapeutic drugs. Their library targeted all known protein kinases, proteins associated with kinases and proteins involved in ceramide metabolism. The screen was carried out in three tumour cell lines (colon, breast and NSCLC) with mutations in KRAS. All the cells were treated with paclitaxel, and also with a drug routinely used to treat that tumour type (5-fluorouracil for colon, doxorubicin for breast and cisplatin for NSCLC). 43 siRNAs that antagonize paclitaxel were identified, and genes with a mitotic-related function were the most prevalent. A total of 26 siRNAs were investigated further. Genes involved in the spindle assembly checkpoint, such as $B U B 1 B$ and $A U R K B$, reduced the mitotic index in cells treated with paclitaxel. The authors reasoned that such siRNAs are likely to enable mitotic progression by weakening the spindle assembly checkpoint, and this should result in polyploidy. 17/20 of the siRNAs that had paclitaxel antagonistic activity in the colon cancer cell line also increased the number of polyploid cells in the absence of paclitaxel. Although less robust in the NSCLC and breast cancer cell lines, eight siRNAs resulted in polyploidy after paclitaxel treatment.

The use of siRNAs that target ceramide synthesis in the screen by Downward and colleagues also revealed the ceramide transport protein, COL4A3BP, as a key determinant of multidrug resistance. siRNAs targeting COL4A3BP resulted in increased sensitivity to paclitaxel, doxorubicin and cisplatin. Moreover, gene-expression data from patients with ovarian cancer before and after treatment with paclitaxel indicated that the

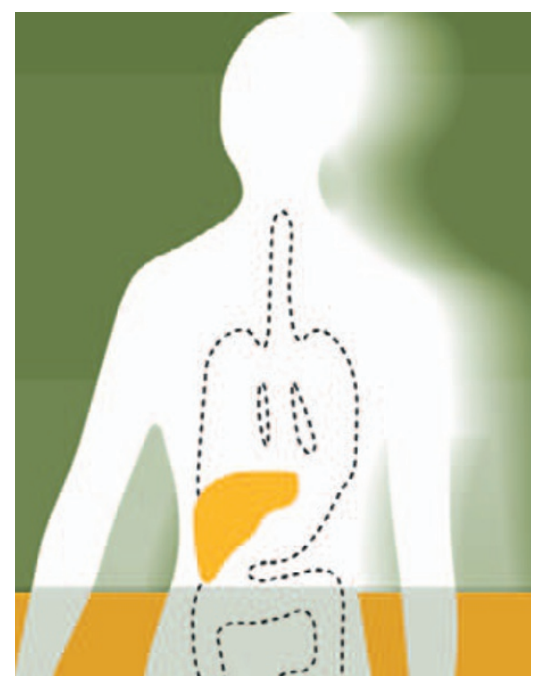

expression of COL $4 A 3 B P$ mRNA increased post treatment. The data indicate that ceramide accumulates in the endoplasmatic reticulum (ER) in the absence of COL4A3BP and induces ER stress, as does treatment with paclitaxel, possibly explaining why the overexpression of COL4A3BP can protect against paclitaxel. Moreover, siRNA against $\beta$-glucosidase, which converts glucosylceramide to ceramide, promotes resistance to paclitaxel, indicating that changes in ceramide transport and synthesis are involved in paclitaxel resistance.

Hopefully the use of siRNA screens will reveal more effective ways for treating tumours that develop drug resistance.

Nicola McCarthy

ORIGINAL RESEARCH PAPERS Whitehurst, A. W. et al. Synthetic lethal screen identification of chemosensitizer loci in cancer cells. Nature $\mathbf{4 4 6}$, 815-819 (2007) | Swanton, C. et al. Regulators of mitotic arrest and ceramide metabolism are determinants of sensitivity to paclitaxel and other chemotherapeutic drugs. Cancer Cell 11, 498-512 (2007) 